\title{
Research on the Visual Brand Image Design of Visual Culture
}

\author{
Fang Zhao ${ }^{1, \text { a }}$ and Lan Luo ${ }^{1, b}$ \\ ${ }^{1}$ City College of WUST, Wuhan, China \\ aZhaofang2016hy@163.com, Pluolan2016hy@163.com
}

Keywords: Visual identity; Design; Brand; Research course

\begin{abstract}
In this study, out of the idea of historical development, in the context of the development of visual culture to build brand image design and visual relationship between interpretation and perception of enlightenment Chinese century-old brand image design development brought on this basis. Conclusion the results of this paper was the view of the Institute as well as a summary of practical significance. Based on the current situation of the country from the perspective of the lack of historical development overall, systematic study of Chinese brand visual identity, it stood high visual culture development, a holistic, multi-dimensional perspective overlooks the visual image design and brand value of the relationship between, and on this basis to explore the visual image design status and role in the modern brand building, and then summed up the past century Chinese brand visual identity of Evolution for the promotion of contemporary art and design programs and the cultural and creative industries development has practical significance.
\end{abstract}

\section{The Influence of Visual Culture on Aesthetic Trend}

To Satisfy the Aesthetic Needs. The United States relies on the existence of human society and human aesthetic activity is a common social phenomenon. Aesthetic activities from the instinctive desire of human beings, the psychological root causes is that people want to own intuitive sense in the primary object of self-consciousness. In addition, the American psychologist Maslow's needs had to be divided into several levels, which also include the people for a sense of order, harmony and beauty needs. Obviously, this is pointing to the aesthetic needs of people in terms of. As can be seen from the early primitive paintings and decorative textures activities, the image is one of the main ways to meet the aesthetic needs of mankind. If the history of visual culture production and dissemination of images deemed to be historical review, the scientific and technological revolution in the history of the period before the occurrence, due to the level of human society, productivity is not high; productivity is limited image, plus intermediary for the single, so resource sharing images has been greatly limited. Therefore, the image in the ancient traditional societies can be said is a relatively scarce resource.

In contemporary visual culture, the image is no longer scarce valuable resources, but everywhere, readily available thing. In modern visual culture shift, the image has become the most important aesthetic object, because innovative technology makes everything possible, the potential aesthetic object can be imaged, and thus more easily perceived by people. Thus, people in the aesthetic image generating activities for the more obvious sense of dependence, it also allows the image propaganda indoctrination functions are highlighted, such as visual brand image design of this feature would have been fully confirmed.

Affect the Aesthetic Trends. Visual impact on the aesthetic and cultural development on the level of aesthetic experience reflects the most obvious. Aesthetic practice, people are often the first contact with through their own senses aesthetic object, aesthetic object gain understanding through visual, auditory, tactile perception, resulting aesthetic image, bring aesthetic experience. In many people's senses, the eyes are the most important part, it can be said of people mostly aesthetic activity to be commenced and completed through visual form. The reason why the visual aesthetic activity is so important, not only because it is a highly clear media, but also in the medium will be endless wealth of information about the world in Vientiane and various objects, events visually demonstrate to humans. Multimedia technology and the popularity of the Internet, is that dynamic, multi-dimensional graphics, graphic design and communication as possible, not only faster graphics, 
images and other information resources transmitted to the audience, and visual, auditory, while the intervention so that the audience You can get multiple aesthetic experience in the aesthetic practice, to produce a variety of aesthetic experience.

The Change between Visual Culture and Aesthetic Trend. Under natural conditions the economy of our traditional society, has given birth to the original visual image to promote its brand awareness, and also the initiation of the design activity as the original commercial design and original advertising tag and other relevant brand image. But the level is subject to commodity development, and science and technology development slow external factors, coupled with the impact of traditional farming culture concept of Chinese ancient primitive visual brand image design activity has been not much of a breakthrough. However, in the long process of development, there is a trend worth noting, is the brand visual identity in the form of a gradual shift from text-based to begin the transition to graphics, image-based.

Can be seen visual culture at the same time of significant change, people's aesthetic activity happening invariably turned to the emergence of this shift is both passive and also active. As an aesthetic subject, his aesthetic practice inevitably influenced by scientific and technological progress to promote under the force generated by the visual culture of change, while this change, people will take the initiative to adjust the aesthetic attitude, to meet the aesthetic practice changes to seek new aesthetic experience and taste, and in the process continue to accumulate and update their aesthetic experience. Of course, as a visual culture constitutes an integral part of the cultural change in the visual and aesthetic shift in the background, the brand's visual identity is constantly updated in the course of development in modern times, variations, showing a variety of development.

\section{The Visual Construction of Brand Image}

Brand image design brand image to build an important part, while the use of visual performance, especially the use of graphics, images, design abstract brand concept interpretation, is the main form since the Modern visual brand image design, It is also extremely popular art and design activities. This artistic design approach in terms of human social and cultural life has a special significance, especially in the commercial field of culture; it shows the important features and value.

The Visual Consumption and Brand Image in Commercial Society. In the context of visual culture, visual aesthetic has become the main way people today aesthetic practice. This visual aesthetic trend in today's business community has demonstrated very clearly. With the commodity economy worldwide continues to develop, the arrival of the consumer society and the formation of consumer culture has become an indisputable fact. In the consumer culture presents many features, the visual consumption can be said to be the most significant. In order to image-based society, consumer behavior has been widely occur in various fields and places, no longer confined to the traditional direct shopping behavior in exchange for the expanded behavior. In comparison, the range of visual consumption to a broader range than shopping, and visual culture in today's highly developed consumer society, to grasp the pulse of visual consumer is savvy companies are paying attention, because "attention itself wealth". How can we make better use of the visual characteristics of consumption, to create real value for the enterprise? Establish a brand image is one effective method. Visual consumption fundamentally an experiential consumption, consumption goods or services during important not just physically and physiologically on consumer satisfaction, more important is the psychological satisfaction. Therefore, the combination of social, commodity market competition and consumer visual characteristics of business, the business to be successful, two things are essential: first, to attract consumers' attention; second is to meet consumer demand, especially the psychological needs. And these two things are related to the company's brand image.

The Inevitability of Visual Construction of Brand Image. As mentioned earlier, the main form of human visual aesthetic activity, and in the consumer society under the context of visual culture, and gradually became the dominant visual consumer consumption behavior of people, all these factors in order to clear out the visual forms brand image design of necessity. As mentioned 
above, in the context of visual culture, it is clear graphics, images of the most intuitive and infectious, but also to convey the effect of the best, which is why in the visual communication design, graphics, images of total use It occupies obvious advantage. Ancient China commercial activities, often in the form of text as the main form of brand recognition, but also the use of graphics, images, fashion design examples, but at least can be traced back to the Northern Song Dynasty, with the West during the Middle Ages in the commercial guilds graphics, images, trademarks time even a little earlier. Visible, graphic, image as the main form of visual brand image design, in among the peoples of the world have already formed a tacit understanding. Build brand image in the form of visual graphics, images and even video, etc., on the one hand by the inherent advantages of these visual forms of the decision, on the other hand is also affected by the development of visual culture, science and technology, steering and other aesthetic approach driven by external forces result.

\section{The Reflection of Visual Brand Image Design}

By studying the foregoing, it is possible to compare Glimpse clear picture of our brand visual identity development. At the same time, since the Republic of China has combined the various historical stages of health and artistic design domestic commodity Diego Economic Development Evolution and other factors to be thinking and analysis, we can get some inspiration from the past century Chinese brand visual identity in the development process. Learn where the beneficial results, to reflect problems found, will be the future development of the domestic brand image design and visual art design a lot helpful.

Design Course. Because the brand image design primarily for corporate brand building and brand marketing services to a commercial art design tools, so the level of socio-economic development, commodity market activity and development of art and design and a series of external factors have a profound impact on the brand visual image design development, and sometimes played a decisive role. This is, from our past century visual brand image design course can be proved. After the reform and opening up, the development direction of the domestic economy gradually shifted from a planned economy of the socialist market economy, the focus shifted to economic construction of the country's development. In this context, the domestic brand image design again and was able to recover rapidly. Raise the level of national economy; improve the domestic people's material living standards, changes in consumer attitudes of the people, openness to deepen and some other external environmental factors for the development of brand visual identity created favorable conditions. And since the eighties, domestic brands are constantly exploring visual image design, forging ahead to mature. Foreign advertising companies stationed in the mature domestic design institutions and design domestic and foreign exchanges are frequent Chinese brand image design career take off development, prosperity sign of prosperity.

Design Effect. Really show domestic brand visual identity under the influence or in the late 1990s to date figures, background information age to achieve. Popularization and development of advanced digital multimedia technology, computers, mobile phones and other network terminal platform, to achieve a set of mobility and multimedia properties, portable, interactive, targeted communication, instant feedback and other characteristics in an idealized new media platforms. From brand communication state of the world's developed countries, the new media, particularly the Internet, digital media, information technology era is bound to be greatly expanded. In the new media world, the audience size is increasing, and based on this differentiation is reunited. Have a clear personality traits from a small audience gradually blurred large social audience is split off, while with a similar value of the pursuit, lifestyle and cultural identity of many individual audience will be aggregated to spread through some platform together, this change in audience the brand image design and implementation of brand strategy now becomes more targeted, no longer blind. In addition, the purpose of visual brand image design from the previous "propaganda told the sake of discussion" to "manufacturing variations, attention" to spread and expand the brand value as the core symbol and charm. It is in such a changing trend in the audience and design, brand visual identity in today's social and cultural life of their growing influence, has become the context of 
globalization of commercial, cultural competition cannot be ignored important part.

\section{Summary}

Visual brand image is the brand culture, brand concepts, brands and brand quality brands such as visual symbol of the internal factors, the fine form design and visual effects to convey a brand of course the audience will have a good first impression, but to the consumer psychology to establish a solid brand image, relying solely on the brand's visual identity is not enough, need more brands and brand quality assurance. However, the brand's visual identity is not "a distinctive sign of the symbol" simple sense of it. You should see the visual brand image design is a systematic integration of the design process, and the visual image of the design is also to be applied in almost all aspects of the brand image of the spread, and its importance can be imagined. For consumers, a brand logo symbolizes the meaning may be more important than the product itself, which in today's consumer society has become an indisputable fact. So, objectively correct look at the role and value of brand visual identity is very important. Chinese visual brand image design is not the Western brand of modern design in a tributary, in the contemporary design of the brand concept copy the Western model is not conducive to the growth and development of Chinese brands. Explore for domestic brand building visual image of the design of the road with Chinese characteristics, China is one of the design development of problems to be solved, Based on the Chinese brand visual identity development context over the past century to sort out and discussed in order to be able to solve this problem may provide a perspective.

\section{References}

[1] Yao Sun day, the Everlasting principles of brand economics .Beijing: Economic Science Press, 2007

[2] Zhang Wei editor, Yang Liming, Yang Minfeng full corporate trademark strategy. - Use, management and protection of the. North Beijing: Law Press .2010

[3] Feng Tianyu, Xiaoming, Zhou Jiming Chinese Cultural History · Part .Shanghai: Shanghai People's Publishing House, 2005

[4] Ma Dongqi, Kang Weimin Chinese Trademarks and culture. Beijing: Chinese Literature Press, 2007

[5] Rui, Li Yan Pro series of digital media art and design. Beijing: National Defense Industry Press, 2012

[6] Lixin Chinese Art History Design Theory. Tianjin: Tianjin People's Publishing House, 2004 